Canadian

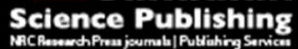

Canadian Journal of Physiology and Pharmacology Revue canadienne de physiologie et pharmacologie

\title{
Cardiac Phenylethanolamine N-methyltransferase: Localization and Regulation of Gene Expression in the Spontaneously Hypertensive Rat
}

\begin{tabular}{|r|l|}
\hline Journal: & Canadian Journal of Physiology and Pharmacology \\
\hline Manuscript ID & cjpp-2015-0303.R1 \\
\hline Manuscript Type: & Article \\
\hline Date Submitted by the Author: & $25-$ Sep-2015 \\
\hline Complete List of Authors: & $\begin{array}{l}\text { Peltsch, Heather; Laurentian University, Biology } \\
\text { Khurana, Sandhya; Northern Ontario School of Medicine, Medical Sciences } \\
\text { Division } \\
\text { Byrne, Collin; Laurentian University, Biology } \\
\text { Nguyen, Phong; Laurentian University, Biology } \\
\text { Khaper, Neelam; Northern Ontario School of Medicine, Medical Sciences } \\
\text { Division } \\
\text { Kumar, Aseem; Laurentian University, Chemistry and Biochemistry } \\
\text { Tai, T.C.; Northern Ontario School of Medicine, Medical Sciences Division }\end{array}$ \\
\hline Keyword: & $\begin{array}{l}\text { phenylethanolamine N-methyltransferase, heart, adrenaline, gene } \\
\text { regulation, spontaneous hypertensive rat }\end{array}$ \\
\hline
\end{tabular}

\section{SCHOLARONE}

Manuscripts 


\section{Cardiac Phenylethanolamine N-methyltransferase: Localization and Regulation of Gene Expression in the Spontaneously Hypertensive Rat}

Heather Peltsch ${ }^{1}$, Sandhya Khurana ${ }^{5}$, Collin J. Byrne ${ }^{1}$, Phong Nguyen ${ }^{1}$, Neelam Khaper ${ }^{4}$, Aseem Kumar ${ }^{2,3}$ and T.C. Tai ${ }^{1,2,3,5}$

${ }^{1}$ Department of Biology, ${ }^{2}$ Department of Chemistry and Biochemistry, ${ }^{3}$ Biomolecular Sciences, Laurentian University, Sudbury, ON, Canada, ${ }^{4}$ Medical Sciences Division, Northern Ontario School of Medicine, Thunderbay, ON, Canada, ${ }^{5}$ Medical Sciences Division, Northern Ontario School of Medicine, Sudbury, ON, Canada

Corresponding author:

Dr. T.C. Tai

Northern Ontario School of Medicine (East Campus), 935 Ramsey Lake Road, Sudbury, ON, P3E 2C6.

Email: tc.tai@nosm.ca

Phone: (705) 662-7239

Abbreviated title: Regulation of cardiac PNMT in SHR 


\section{ABSTRACT}

Phenylethanolamine N-methyltransferase (PNMT) is the terminal enzyme in the catecholamine biosynthetic pathway responsible for adrenaline biosynthesis. Adrenaline is involved in the sympathetic control of blood pressure; it augments cardiac function by increasing stroke volume and cardiac output. Genetic mapping studies have linked the PNMT gene to hypertension. This study examined the expression of cardiac PNMT and changes in its transcriptional regulators in the spontaneously hypertensive (SHR) and wild type Wistar-Kyoto (WKY) rats. SHR exhibit elevated levels of corticosterone, and lower levels of the cytokine IL-1 $\beta$, revealing systemic differences between SHR and WKY. PNMT mRNA was significantly increased in all chambers of the heart in the SHR, with the greatest increase in the right atrium. Transcriptional regulators of the PNMT promoter show elevated expression of Egr-1, Sp1, AP-2 and GR mRNA in all chambers of the SHR heart, while protein levels of Sp1, Egr-1 and GR were elevated only in the RA. Interestingly, only AP-2 protein-DNA binding was increased, suggesting it may be a key regulator of cardiac PNMT in SHR. This study provides the first insights into the molecular mechanisms involved in the dysregulation of cardiac PNMT in a genetic model of hypertension.

Key Words: phenylethanolamine N-methyltransferase, heart, gene transcription, adrenaline, SHR 


\section{INTRODUCTION}

Catecholamines (CAs) are neurotransmitters that function in blood pressure homeostasis (Axelrod 1976, Bühler et al. 1980). The CA adrenaline is a powerful vasoconstrictor involved in the sympathetic control of blood pressure, and augments cardiac function by increasing heart rate and cardiac output (Borkowski and Quinn 1984). Phenylethanolamine N-methyltransferase (PNMT; EC 2.1.1.28), the terminal enzyme in the CA biosynthetic pathway, is responsible for the biosynthesis of adrenaline. The elevation of plasma adrenaline in animal models and humans with essential hypertension has been correlated with increased PNMT activity (Borkowski and Quinn, 1984; de Champlain et al., 1976; Goldstein, 1983; Saavedra et al., 1976). Genetic mapping has linked the PNMT gene to hypertension, with no sequence polymorphisms identified, suggesting that increases in PNMT may be due to altered transcriptional regulation of the gene (Koike et al, 1995). Furthermore, disruption of conserved regulatory motifs in the PNMT promoter by common functional genetic variation may lead to changes in physiology (Rodríguez-Flores et al. 2010). Previously, we demonstrated altered transcriptional regulation of adrenal PNMT in the spontaneously hypertensive rat (SHR), likely contributing to the hypertension observed in this rodent model (Nguyen et al. 2009).

Although the primary source of circulating adrenaline is the adrenal gland, several studies report PNMT and adrenaline in the heart (Esler et al., 1991; Kennedy and Ziegler, 1991; Ziegler, Bao et al., 2002). Although, the importance of CAs in augmenting heart function is established, and they are obligatory in fetal heart development (Huang et al., 2005; Thomas et al., 1995), the role of cardiac adrenaline in adults is unclear. CAs in the heart is suggestive of an independent cardiac adrenergic system to cope with stress, and regulate blood pressure, which could play a 
role in the pathophysiology of hypertension (Kennedy et al., 1993; Krizanová et al., 2001; Kvetnansky et al., 2004).

Several transcription factors activate and regulate the adrenal PNMT gene including Egr1 (early growth response-1), AP-2 (activator protein-2), Sp1 (specificity protein 1), and GR (glucocorticoid receptor); these work independently, or cooperatively, to induce PNMT (Ebert and Wong, 1995; Ebert et al., 1998; Ebert et al., 1994; Morita et al., 1996; Tai et al., 2002; Wong et al., 1998). PNMT can be neurally induced in vivo through cholinergic activation, regulated by the sympatho-adrenal (SA) axis; the induction of PNMT by this pathway is mediated by synergism between the transcription factors Egr-1 and Sp1 (Morita et al., 1996; Morita and Wong, 1996; Tai et al., 2001; Wong et al., 2002; Wong et al., 1993). PNMT is also hormonally induced by glucocorticoids (GCs), and activated-GR can interact with Egr-1 or Ap-2 to synergistically induce PNMT through a combination of neural and hormonal regulation (Her et al., 2003; Tai et al., 2002; Wong et al., 1992; Wong et al., 1998). Interestingly, GCs also stabilize PNMT post-translationally by regulating the concentration of S-adenosyl-methionine (Wong et al., 1985).

The expression of cardiac PNMT is GC-dependent (Kennedy and Ziegler, 1991; Krizanova et al., 2007; Krizanová et al., 2001; Kvetnansky et al., 2004). However, during fetal development, cardiac PNMT is greatest prior to sympathetic innervations and presence of GCs, implying multiple mechanisms for it's regulation (Kennedy and Ziegler 2000). Although it's unclear if neural or hormonal regulation predominates in the heart, independent chambers appear to be modulated differently in a stress-dependent manner (Tillinger et al. 2006). 
In this study, the regulation of cardiac PNMT was examined in the SHR compared to normotensive WKY; the SHR is a genetic model that shares several features of essential hypertension in humans (Frohlich 1986). This study provides first evidence that cardiac PNMT mRNA is significantly upregulated in the heart of a rodent model of hypertension, the SHR. Furthermore, regional expression of PNMT was observed, with the atria showing higher expression compared to the ventricles. The mRNA and protein levels of the transcriptional regulators Sp1, GR, and Egr-1 were also elevated in the right atrium; interestingly, only AP-2 showed increased protein-DNA binding. The results suggest that increased PNMT expression in the SHR heart is mediated partly by altered transcriptional regulation, and AP-2 is an important regulator of cardiac PNMT. Moreover, the cardiac adrenergic system may additionally contribute to the cardiovascular dysregulation observed in SHR. 


\section{METHODS}

\section{Animals}

All animal procedures were approved by the Laurentian University Animal Care Committee and were performed in accordance with guidelines from the Canadian Council on Animal Care. Spontaneous hypertensive rats (SHR) and Wistar-Kyoto rats (WKY) $(n=6)$ were obtained from Taconic Farms (Germantown, NY) at 12-weeks of age. Animals were housed in pairs within plexiglass cages with corn bedding for the duration of the study. Food (Harlan Teklad standard rat chow) and water were supplied ad libitum.

\section{Blood Pressure Measurements}

Blood pressure measurements were performed as previously described (Nguyen et al. 2009). Briefly, animals at 13 weeks of age were subjected to daily blood pressure measurements via a non-invasive tail-cuff plethysmography method (CODA 6, Kent Scientific, Torrington, CT) (Feng et al. 2008). Following one week of acclimation period, 30 consecutive blood pressure measurements were taken over 30 minutes. All measurements were conducted between 8:00 am and 2:00 pm during the light cycle.

\section{Tissue Collection}

At 16-weeks of age, animals were anesthetised with intraperitoneal administration of ketamine (Ketalean; Bimeda, Cambridge, ON) and xylazine (Rompun; Bayer, Etobicoke, ON) and then sacrificed by immediate decapitation. Hearts were frozen on dry ice, and stored at $80^{\circ} \mathrm{C}$ until use. The heart chambers were later dissected into left atrium (LA), right atrium (RA), left ventricle (LV) and right ventricle (RV) sections, avoiding the interatrial and interventricular septum. 


\section{Preparation of heart homogenates for RNA extraction}

Total RNA was isolated from each chamber of the heart using TRI REAGENT ${ }^{\mathrm{TM}}$ (Sigma-Aldrich Corp., MO, USA) as per manufacturers protocol. The TissueLyser (Qiagen, Mississauga, ON, CA) was used to mechanically disrupt the tissue for RNA extraction, and isolated RNA was pelleted and dissolved in DEPC-treated, nuclease-free water. RNA concentrations were determined by measuring the absorbance at $260 \mathrm{~nm}$ (NanoDrop; Nanodrop Technologies, Wilmington, DE).

\section{PNMT and transcription factor mRNA}

PNMT and transcription factor mRNA was quantified using reverse-transcriptionpolymerase chain reaction (RT-PCR). For RT-PCR, $2 \mu \mathrm{g}$ of total RNA was treated with DNase1 following the manufacturer's protocol (Sigma-Aldrich Corp., MO, USA). Following DNase treatment, the RNA was reverse transcribed with RevertAid $^{\mathrm{TM}} \mathrm{H}$ M-MuLV Reverse Transcriptase as per the manufacturer's protocol (Fermentas, Burlington, ON, CA). PCR amplification was performed on 80 - $250 \mathrm{ng}$ of reverse transcribed product using the Promega GoTaq polymerase (Promega Corp., Madison WI, USA). Specific 5`and $3^{`}$ primers included: PNMT, $5^{` C A G A C T T C T T G G A G G T C A A C C G ~ 3 ` a n d ~ 5 ` A G C A G C G T C G T G A T A T G A T A C ~ 3 ` ; ~}$ Sp1, 5` TTTACCAGCAGCGGATCATCAG 3` and 5` TGAAGGCCAAGTTGAGCTCCAT 3`; Egr-1, 5`CTGACATCGCTCTGAATAACG 3` and 5`CTCAACAGGGCAAGCATACG 3`; AP-2, 5`TTAAGAAAGGCCCTGTGTCCCT 3`and 5`AAGCCATGGGAGATGAGGTTGA 3`; GR, 5`GACCTCTTGAAGGATTTGGAG 3`and 5`GCTTACATCTGGTCTCATTCC 3`; and $28 \mathrm{~S}$ RNA, $5^{`}$ GACCTCAGATCAGACGTGGC $3^{`}$ and $5^{`}$ ACCTCTTAACGGTTTCACGCC 3`. PCR products were resolved on 1.5\% agarose gels stained 
with ethidium bromide. Gels were imaged using the Chemidoc XRS system (BioRad, Hercules, CA) and semi-quantitative comparisons performed by computerized densitometry techniques using the Quantity One Image Software (BioRad, Hercules, CA). PNMT and transcription factor mRNA expressions were normalized respective to $28 \mathrm{~S}$ RNA expression, and then relative to control set to unity.

\section{Preparation of heart homogenates for protein extraction}

Heart tissues were homogenized using the TissueLyser (Qiagen, Mississauga, ON, CA) in RIPA lysis buffer containing 25mM Tris- $\mathrm{HCl} \mathrm{pH}$ 7.6, 150mM NaCl, 0.1\% SDS, 2mM EDTA, $1 \%$ sodium deoxycholate, $1 \%$ NP-40 with $0.5 \mathrm{mM}$ phenylmethylsulfonyl fluoride (PMSF) and Complete Mini-EDTA free protease inhibitor cocktail tablets (Roche Diagnostics, Indianapolis, $\mathrm{IN})$. Lysates were incubated on ice for $10 \mathrm{~min}$ and centrifuged at $12,000 \mathrm{xg}$ for $20 \mathrm{~min}$ at $4^{\circ} \mathrm{C}$. Supernatant was isolated and protein concentration was determined by the Bradford method. Protein extracts were stored at $-80^{\circ} \mathrm{C}$ until use.

\section{Western Blot Analysis}

Proteins $(200 \mu \mathrm{g})$ were resolved using 12.5\% sodium dodecyl sulphate-polyacrylamide gel electrophoresis (SDS-PAGE) and then transferred to polyvinylidine fluoride (PVDF) (Whatman, Sanford, ME) membranes. Ponceau S staining (Sigma-Aldrich Corp., MO, USA) was performed to confirm equal protein loading. Membranes were blocked in 5\% skimmed milk in TBS-T (10mM Tris- $\mathrm{HCl} \mathrm{pH} 8.0,150 \mathrm{mM} \mathrm{NaCl}, 0.05 \%$ Tween-20). Following washes with TBS-T, membranes were incubated with rat polyclonal Egr-1 (1:1000; C-19), Sp1 (1:2500; PEP2), GR (1:2000; M-20) antibodies (Santa Cruz, CA, USA), or mouse monoclonal AP-2 (1:2000; MAB3784) antibodies (Millipore, Billerica, MA) overnight at $4^{\circ} \mathrm{C}$. Membranes were washed again with TBS-T and incubated with horseradish peroxidase conjugated anti-rabbit or anti- 
mouse IgG (1:5000; Santa Cruz, CA, USA) for 1 hour at room temperature. After washes in TBS-T, proteins were detected by enhanced chemiluminescence (Haan and Behrmann 2007). Proteins were quantified by computerized densitometry of the autoradiograms using the Chemidoc and Quantity One Image Software (BioRad, Hercules, CA).

\section{Gel mobility shift assay}

Gel mobility shift assays (GMSAs) were performed using double-stranded oligonucleotides specific for the Sp1, GR, AP-2 and Egr-1 binding sites within the PNMT promoter as described previously (Tai et al. 2007). Oligonucleotides were 5 'end-labeled with [ $\delta^{-}$ $\left.{ }^{32} \mathrm{P}\right]$ ATP using T4 polynucleotide kinase (Fermentas, Burlington, ON, CA). $50 \mu \mathrm{g}$ of whole cell protein extracts were mixed with the ${ }^{32} \mathrm{P}$-labeled probes in $25 \mu \mathrm{L}$ of binding buffer and $4 \mu \mathrm{g}$ poly dA-dT (Sigma-Aldrich Corp., MO, USA). Following incubation on ice for 60 min, protein/DNAbinding complexes were resolved by separation on $7 \%$ polyacrylamide gels, dried and exposed to film. The autoradiograms were compared by computerized densitometry as described for western blot analysis.

\section{Plasma levels of Corticosterone and Cytokines}

Trunk blood was collected in EDTA-coated blood collection vials (Becton Dickinson, Mississauga, CA) and centrifuged at 1,500 x g for $20 \mathrm{~min}$. Plasma was collected, aliquoted and stored at $-80^{\circ} \mathrm{C}$ until use. Corticosterone and cytokine levels were determined in duplicate for each sample ( $n=4-6$ per group) by Milliplex immunodetection assays following the manufacturer's protocol (Millipore, Billerica, MA).

\section{Statistical Evaluation}


All data are presented as the mean $\pm \operatorname{SEM}(n=4-6)$. Statistical significance between WKY and SHR was determined by unpaired t-tests or analysis of variance with post-hoc comparisons using the Student-Newman-Keuls multiple comparisons test (GraphPad InStat; La Jolla, CA). Results were considered statistically significant with values of $p \leq 0.05$. 


\section{RESULTS}

\section{Physiological Measurements of WKY and SHR}

To confirm the phenotype of the animals, blood pressure and heart rate were measured at 16-weeks of age in age-matched WKY and SHR animals. Significant elevations in blood pressure and heart rate were observed in the SHR compared to WKY (Fig. 1). Average systolic and diastolic blood pressure in SHR was $64.6 \mathrm{mmHg}(\mathrm{WKY}: 121.5 \pm 1.7 \mathrm{mmHg}$, SHR: $186.1 \pm$ $3.0 \mathrm{mmHg} ; p<0.001)$ and $49.2 \mathrm{mmHg}(\mathrm{WKY}: 81.7 \pm 1.7 \mathrm{mmHg}, \mathrm{SHR}: 130.9 \pm 4.0 \mathrm{mmHg} ; p<$ 0.001) higher than WKY respectively. Consequently, mean arterial blood pressure was increased in SHR by an average of $54.2 \mathrm{mmHg}(\mathrm{WKY}: 94.7 \pm 1.6 \mathrm{mmHg}, \mathrm{SHR}: 148.9 \pm 3.6 \mathrm{mmHg} ; p<$ 0.001) compared to WKY. Finally, heart rate measurements showed an increase of 31.4 beats per minute $(\mathrm{bpm})(\mathrm{WKY}: 306.3 \pm 7.4 \mathrm{bpm}$, SHR: $337.8 \pm 3.6 \mathrm{bpm} ; p<0.01)$ in SHR. Therefore, these results confirm the differences in phenotype between SHR and WKY, and verify SHR as a genetic model for hypertension.

\section{Changes in plasma corticosterone and cytokines in SHR}

The regulation of PNMT by GCs has been previously shown in adrenal tissue, in PC12 cell (an adrenal derived cell line) and heart tissue (Krizanová et al. 2001, Ziegler et al. 2002, Tai et al. 2002, Nguyen et al. 2009). Plasma levels of the naturally occurring GC, corticosterone, was examined in WKY and SHR to investigate the activity of the hypothalamic-pituitary-adrenal (HPA) axis in these animals. Kvetnansky et al. 2004 reported that in corticosterone knockout mice the stress-induced increase in PNMT mRNA was abolished, indicating that corticosterone is a key regulator of PNMT in the heart under stress. SHR show significantly higher concentrations of plasma corticosterone than WKY (Fig. 2A). This is indicative of hyperactivity of the HPA axis and/or dysregulation of glucocorticoid synthesis and release in SHR. 
GCs have been implicated in the regulation of several cytokines (Scheinman et al., 1995). To examine the influence of GCs on the immune response, several cytokines were investigated to assess variations between the WKY and SHR. A screening of several plasma cytokines was performed (Fig. 2B) to determine the effects of elevated GCs in SHR on cytokine production, and which cytokines may be linked to the hypertensive phenotype of SHR. The chemokine monocyte chemoattractant protein-1 (MCP-1) showed no significant changes in SHR compared to WKY, neither did the cytokines IL-12p70, IL-18, IL-2, IL-6, IL-10, GMCSF, IFN $\gamma$ and IL10, however they showed a trend toward decreased levels. The cytokine IL-1 $\beta$ was significantly reduced in SHR. Together, these results demonstrate that there are systemic differences between WKY and SHR in HPA axis regulation resulting in elevated levels corticosterone and likely decreased production of several cytokines in circulation.

\section{Cardiac PNMT mRNA expression in the SHR}

The expression of cardiac PNMT was analyzed using RT-PCR in WKY and SHR hearts. The PNMT gene can undergo alternative splicing resulting in an intronless transcript leading to a functional protein or an intron-retaining transcript leading to a truncated protein that is nonfunctional (Unsworth et al., 1999; Ziegler et al., 2002). The presence of GCs has been implicated in the predominance of intronless PNMT and stabilizing its enzymatic activity in adrenal tissue (Evinger et al., 1992; Ross et al., 1990; Wong et al., 1992; Ziegler et al., 2002). However GC stabilization of cardiac PNMT appears to not be as prevalent in the heart likely due to the minimal sustained adrenaline production compared to the adrenal (Ziegler et al. 2002). PNMT mRNA expression for both the intronless and intron-retaining forms were detected in the hearts of SHR and WKY. All four chambers of the heart from the SHR showed significant elevations in intronless PNMT (active) mRNA expression compared to WKY (1.4-2.0-fold) (Fig. 3A and 3B). 
Intron-retaining PNMT mRNA levels were similar in the hearts of SHR and WKY (Fig. 3A and 3C) and it was distributed equally in SHR hearts and in WKY hearts, with the exception of the right atrium (RA) of SHR having slightly lower expression. The distribution of intronless PNMT in the heart of WKY reveals no significant differences between the ventricles and atria. Conversely, in SHR, the atria have a higher expression of PNMT than the ventricles, and the RA of SHR has the highest level of PNMT gene expression $(2.0$-fold; $p<0.001)$. Previous studies have shown that PNMT mRNA is present in both cardiac atria and ventricles of Sprague-Dawley rats with the atria containing higher levels in comparison to the ventricles (Krizanová et al. 2001, Kvetnansky et al. 2004). The highest levels of PNMT mRNA at both basal and stress conditions, however, were observed in the left atrium (LA) (Kvetnansky et al. 2004). Although basal conditions in previous studies have demonstrated unequal distribution of PNMT mRNA in Sprague-Dawley rats, intronless PNMT mRNA expression in WKY show an equal distribution across heart chambers. (Krizanová et al. 2001, Kvetnansky et al. 2004). Moreover, the degree of difference in expression between the left and right atria, and the atria compared to the ventricles, was greater in Sprague-Dawley rats than that observed in the current study for the SHR heart. This study demonstrates for the first time that the genetic rodent model of hypertension, SHR, exhibits significant elevations in cardiac PNMT mRNA expression in heart tissue. Furthermore, WKY reveal an equal distribution of intronless PNMT mRNA across heart chambers, while the SHR display differential expression of cardiac PNMT in the heart, with the highest expression of PNMT mRNA in the RA.

\section{Cardiac PNMT gene transcriptional regulators in the SHR}

To determine whether the increase in PNMT expression in SHR hearts is the due to altered transcriptional regulation of the promoter, the gene expression of specific transcription 
factors that regulate PNMT were examined by RT-PCR. Gene expression of Sp1, GR, AP-2 and Egr-1 was detected in all chambers of the hearts of WKY and SHR (Fig. 4). Investigation into the distribution of mRNA expression for the transcriptional regulators revealed differential expression of these transcription factors within the heart of SHR. Expression of Sp1 mRNA was significantly increased in all chambers of the SHR heart except the LA when compared to WKY, with the highest expression in the RA $(1.8$-fold; $p<0.01)$ and LV (1.7-fold; $p<0.01)$. In WKY, the levels of Sp1 mRNA were slightly lower in the RV and RA, compared to LA and LV. The GR mRNA expression was elevated in all chambers of SHR, with the most significant increase in the ventricles (LV: 3.1-fold, RV: 3.0-fold; $p<0.01$ ) compared to the atria (LA: 1.7-fold, RA: 1.9-fold; $p<0.05)$. A similar distribution of the GR was observed in WKY hearts. AP-2 mRNA expression was significantly higher in all chambers of the SHR hearts $(1.8$-2.4-fold; $p<0.001)$, and also when compared to WKY. However, in WKY the distribution of AP-2 showed no significant differences between chambers. Lastly, analysis of Egr-1 mRNA distribution in the hearts of WKY revealed an equal distribution of Egr-1; in contrast, the hearts of SHR revealed increased expression in each chamber compared to WKY, with the greatest fold increase in the RA (2.6-fold; $p<0.001)$.

\section{Changes in transcription factor protein levels and activation in the SHR}

To determine whether Sp1, GR, AP-2 and Egr-1 protein expression corresponded to respective mRNA expression, western blot analysis was performed on total protein extracts isolated from WKY and SHR hearts. Western blot analyses of protein levels in the four heart chambers for the transcriptional regulators Sp1 (3.5-fold; $p<0.001)$, Egr-1 (1.5-fold; $p<0.05)$, and the GR (2.0-fold; $p<0.05)$, revealed significant elevations in the RA of SHR when compared to the WKY (Fig. 5). In addition, protein levels of Sp1 were significantly elevated in 
the LV (4.0-fold; $p<0.001)$ and the RV (1.9-fold; $p<0.01)$, and Egr-1 protein levels in the LA were elevated as well $(1.5$-fold; $p<0.05)$ of the SHR.

Protein levels of the transcription factors did not consistently correlate with mRNA levels. Sp1 protein levels followed a similar trend to mRNA expression; however the fold increases were greater at the protein level. In contrast, protein levels of the GR only correlated with mRNA in the RA of SHR and the elevated mRNA expression of AP-2 observed in SHR hearts was not observed in protein levels. Similarly, Egr-1 mRNA expression was significantly elevated in SHR hearts, however this was not reflected in protein levels and the increase of Egr-1 protein in the RA and LA were not as great as compared to the increases in mRNA.

The activation status of a protein dictates its functionality in the regulation of genes. To assess the activation status of the transcriptional regulators of PNMT in WKY and SHR heart tissues, GMSAs were performed for each transcription factor using whole cell extracts and ${ }^{32} \mathrm{P}$ labeled oligonucleotides encoding the consensus binding sequence for each transcription factor (Sp1, GR, AP-2, Egr-1) (Fig. 6). The transcription factors Sp1 and Egr-1 can be activated following phosphorylation by cAMP-protein kinase A (PKA) and protein kinase $\mathrm{C}$ (PKC) pathways to regulate the PNMT gene (Tai and Wong 2003). Similarly, AP-2 can be activated after phosphorylation by the phorbol-ester and diacylglycerol-activated PKC and the cAMPPKA pathways to mediate transcriptional regulation (Imagawa, et al, 1987). The GR, an intracellular receptor, must be activated by GC binding, which results in the translocation of activated-GR to the nucleus, whereby it can regulate the transcription of many genes (Yamamoto 1985, Funder 1997), including PNMT (Tai et al. 2002). 
SHR hearts show a similar degree of PNMT promoter binding with Sp1, Egr-1 and the GR as seen in WKY hearts, except a slightly lower binding of Sp1 in the LA. Interestingly, AP-2 demonstrates significantly increased binding $(1.3-1.5$-fold; $p<0.05)$ to its cognate promoter sequence in SHR hearts, indicating an increased activation of AP-2 in SHR. Previous studies show that GCs are required for PNMT promoter activation by AP-2 (Ebert et al. 1998, Ziegler et al. 2002). Thus, AP-2 appears to be a key transcriptional regulator of cardiac PNMT in SHR hearts and the elevation of plasma corticosterone in these animals may facilitate this increase in AP-2 activation. 


\section{DISCUSSION}

The neurotransmitter/neurohormone adrenaline is secreted at basal levels to regulate blood pressure at a steady state, and during a stress response, to activate several physiological processes that prepare the body to cope with the stressor (Axelrod 1976, Bühler et al. 1980, Borkowski and Quinn 1984). In the heart, adrenaline influences cardiac function by increasing stroke volume and heart rate via cognate $\beta_{1}$-adrenergic receptors on myocytes and PKAdependent pathways, which subsequently increases cardiac output and ultimately blood pressure (Borkowski and Quinn, 1984; Freyschuss, et al, 1988). Stress initiates the 'fight or flight' response which is an adaptive reaction involving catecholamine's, among other hormones, that improve cardiovascular function; this response is mediated by the sympatho-adrenal (SA) axis and the hypothalamic-pituitary-adrenal (HPA) axis (Axelrod, 1976; McEwen, et al, 1986; Reisine, 1984). It is usually an acute response, however because adrenaline can accumulate in sympathetic nerves and be released long after the stressor is removed, a prolonged or chronic effect on the cardiovascular system can occur (Rumantir et al. 2000). Elevated plasma levels of adrenaline have been associated with hypertension in the SHR, and humans with hypertension; furthermore chronic administration of adrenaline to rats showed prolonged elevation of blood pressure (Majewski et al. 1981, Goldstein 1983, Jablonskis and Howe 1994). Adrenaline has been found to be released from the heart as sympathetic spill-over in essential hypertension, and sympathetic hyperactivity has been linked with the pathogenesis of hypertension supporting the adrenaline hypothesis of essential hypertension (Anderson et al., 1989; Brown and Macquin, 1981; Grassi et al, 2006; Majewski, 1981; Rumantir et al., 2000).

Both acute and chronic stressors activate the HPA and SA axes, resulting in the release of GCs from the adrenal cortex which influence the transcriptional regulation of PNMT, the 
enzyme which is directly responsible for the conversion of noradrenaline to adrenaline (Tai et al. 2002, Her et al. 2003, Wong 2006). Elevated PNMT gene expression is increased under several stress conditions, and in animal models of hypertension, in the heart, brain, and adrenal glands (Saavedra et al. 1976, Krizanová et al. 2001, Kvetnansky et al. 2004, Tillinger et al. 2006, Krizanova et al. 2007, Nguyen et al. 2009).

Several studies have investigated cardiac PNMT in fetal heart development, and during the stress response (Zhou et al. 1995, Ebert et al. 1998, Ebert and Thompson 2001, Krizanová et al. 2001, Kvetnansky et al. 2004, Krizanova et al. 2007). However little is known regarding the molecular mechanisms involved in the regulation of cardiac PNMT in an adult model of essential hypertension. The present study was undertaken to investigate the transcriptional regulation of cardiac PNMT in the SHR rodent model of hypertension

The SHR exhibit elevated blood pressure (Fig.1), and enhanced HPA axis activity that is reflected in significantly elevated plasma levels of the stress hormone corticosterone, compared to WKY (Fig. 2A). In addition, SHR have been reported to have increased levels of CRF mRNA and plasma ACTH (Djordjevic et al., 2007). Hyperactivity of the HPA axis observed in SHR may be indicative of a chronic state of stress that is likely contributing to elevated expression of PNMT and may illicit harmful physiological effects on the cardiovascular system and blood pressure regulation.

Inflammation, caused by a stressor resulting in the production of proinflammatory cytokines, has been associated with many chronic diseases, including hypertension (Edwards et al. 2007). The HPA axis can modulate the immune system by $\mathrm{GC}$ and $\mathrm{CA}$ release from the adrenal medulla (Rosmaninho-Salgado et al., 2007). Several cytokines have been shown to be 
induced by CAs, and cytokines have also been shown to induce CA release (Rabkin 2009). The role of inflammation in the genesis of essential hypertension is well established (Coffman 2011). In humans, some cytokines are expressed more highly in pre-hypertensive and hypertensive groups than in normotensive groups (Chrysohoou et al., 2004; Derhaschnig et al., 2002; Parissis et al., 2002). Our study did not identify significant differences in the circulating levels of the cytokines analyzed between WKY and SHR animals. IL-1 $\beta$ was the only cytokine that was found to be present at lower levels in SHR than WKY, and this finding is not inconsistent with the literature. Numerous studies in rats have demonstrated unique profiles of circulating cytokines in SHR and WKY; however, findings have not always been consistent. For example, studies have reported both higher or lower plasma levels of IL-1 $\beta$ and IL-6 in SHR than their WKY counterparts in 30-32 week old rats (Miguel-Carrasco et al., 2010; Sanz-Rosa, Cediel, et al., 2005a; Sanz-Rosa, Oubiña, et al., 2005b). Another investigation compared 4 week old WKY and SHR and found no difference in plasma levels of IL-1 $\beta$, IL-6, and TNF- $\alpha$ (Chiba et al., 2012). Although not explaining all conflicting reports, age appears to be an important factor for the development of immune changes with hypertension. In SHR, levels of some circulating cytokines increase with age and appear to coincide with the onset of hypertension (Chou et al., 1998).

Similar disagreements was also observed in studies of human hypertensives, which showed increased circulating levels of IL-1 $\beta$ in one study and decreased levels in another (Dalekos et al., 1997; Dalekos et al., 1996; Peeters et al., 2001). It has been suggested that genetic differences in study populations may account for the variability where these differences are the cause of differences in cytokine expression and are wholly a characteristic of hypertension. Further, the elevated level of corticosteroid seen in our model is a conceivable 
contributor to the trend toward immune-suppression, since GCs can repress the biosynthesis of numerous cytokines (Scheinman et al. 1995). The bidirectional interaction of the HPA axis, GCs and immune response are also recognized, making this a more complicated phenomenon that can alter the physiology to have cumulative or independent effects (Uchoa et al. 2014).

Previous in vivo studies have focused on the localization and regulation of PNMT in the hearts of rats and mice under basal and stress conditions (Gavrilovic et al., 2009; Gavrilovic et al., 2010; Krizanova et al., 2007; Krizanová et al., 2001; Kvetnansky et al., 2004). Kvetnansky and coauthors (2004) have shown in Sprague-Dawley rats that the LA has the highest basal expression of PNMT mRNA and protein, followed by the RA, with the ventricles expressing much lower basal amounts of PNMT mRNA and protein. Our findings show that in SHR hearts the atria most highly express intronless PNMT, which codes for the active form of the PNMT enzyme (Unsworth et al. 1999, Ziegler et al. 2002), followed by the ventricles which exhibit slightly lower PNMT expression comparatively. This may be attributed to the fact that the RA is highly innervated by sympathetic neurons, as the sinoatrial (SA) and atrioventricular (AV) nodes preside in the RA (Moorman et al., 1998). Increased sympathetic stimulation, which is characteristic of SHR, is known to result in increased SA node firing rate, thereby increasing the heart rate and force of contraction (Van Stee 1978). Moreover, the RA plays a critically important physiological role in initiating the cardiac cycle and serves as an ideal target whereby cardiovascular regulation can occur due to the high degree of sympathetic and parasympathetic innervations (Van Stee 1978).

Results from this study show that intronless PNMT is predominant, while the intronretaining form is less expressed with slight differences in between and within various chambers of the hearts of WKY and SHR. The differential expression of intronless PNMT mRNA was 
evident, and in agreement with a prior studies demonstrating that PNMT gene expression is differentially modulated in a stress-dependent manner, with the presence of GCs favoring the intronless form (Unsworth et al. 1999, Kvetnansky et al. 2004, Tillinger et al. 2006). There was however differences in expression levels in specific chambers, with other papers showing higher PNMT in LA while our data reveals higher expression in the RA. The basal expression of PNMT in the ventricles is also higher in this model compared to other reports. These differences are likely linked to cardiac PNMT being regulated by both GC-dependent and independent mechanisms, the animal model used, or stressor administered. Also, it has been suggested that in the atria PNMT mRNA regulation may be focused on coping to stress-induced conditions; however PNMT in the ventricles may be involved in the basic metabolic demands of the heart itself (Tillinger et al. 2006). Interestingly, alterations in PNMT activity were noted in LV in electro-stimulation stressed rats, and when the stress was followed with swim exercise. PNMT levels were increased much more in WKY than SHR (Rupp et al. 1984). Thus it is plausible that the increases in PNMT might be stressor and stimuli dependent.

The key transcriptional regulators (Sp1, GR, AP-2 and Egr-1) were all increased and showed differential expression within the SHR heart compared to WKY (Fig. 4). These expression differences may be due to activation of several different intracellular signaling pathways involved in stimulating these transcription factors. Interestingly, AP-2 has been identified as a novel cardiac regulator of apoptosis in idiopathic-dilated cardiomyopathy in rat cardiomyoctyes and several studies support the hypothesis that chronic $\beta$-adrenergic stimulation of the cAMP-dependent signaling pathway by elevated CAs contributes to the altered expression of functionally relevant cardiac genes in the failing heart (Müller et al., 2004; Müller et al., 2000). Therefore, the changes in the transcriptional regulators of PNMT observed in the SHR 
heart may be linked to the altered adrenergic function previously noted in SHR. Interestingly, although increases in activated GR/DNA binding complex were not observed in any heart chamber, AP-2/DNA binding complex were observed in all SHR heart chambers, which has been associated with the requirement of activated-GRs for promoter binding (Ebert et al. 1998, Wong et al. 1998).

In summary, the SHR model exhibits an elevated expression of cardiac PNMT in all chambers of the heart, along with associated changes in its transcriptional regulators. The mRNA and protein analyses demonstrate the greatest changes in RA of SHR, with the highest PNMT, and significant increases in Sp1, GR and Egr-1. Only AP-2 demonstrated increased binding to its cognate promoter sequence for all chambers of the SHR heart, and suggests that AP-2 may be a critical regulator of cardiac PNMT at later stages in life for the genetic rodent model of hypertension. These observations, along with previously published literature on transcriptional regulation of PNMT in the adrenal gland, and increased adrenaline synthesis, contribute to the altered adrenergic function in SHR and provide a potential genetic basis for the pathogenesis of hypertension (Kvetňanský et al. 1995, Tai et al. 2007, Nguyen et al. 2009).

In conclusion, the results of this study provide insight into a novel molecular mechanism for the dysregulation of PNMT in the heart of SHR. Furthermore, the provide evidence that dysregulation of cardiac PNMT may be in part contributing to the genetic basis for the pathogenesis of hypertension in SHR, and thereby implicate heart tissues in a cardiac adrenergic system for cardiovascular regulation. 


\section{Acknowledgements}

This work was supported by funding from the Canadian Institutes for Health Research (Grant IHD98766) and the NOSM Research Development Fund. 


\section{References:}

Anderson, E.A., Sinkey, C.A., Lawton, W.J., and Mark, A.L. 1989. Elevated sympathetic nerve activity in borderline hypertensive humans. Evidence from direct intraneural recordings. Hypertension 14(2): 177-183. doi: 10.1161/01.HYP.14.2.177.

Axelrod, J. 1976. Catecholamines and Hypertension. Clin. Sci. Mol. Med. 51: 415s-421s.

Borkowski, K., and Quinn, P. 1984. Adrenaline and the development of genetic hypertension. J Hypertens Suppl 2(3): S81-3.

Brown, M.J., and Macquin, I. 1981. IS ADRENALINE THE CAUSE OF ESSENTIAL HYPERTENSION? Lancet 318(8255): 1079-1082. doi: 10.1016/S0140-6736(81)91279-4.

Bühler, F.R., Kiowski, W., van Brummelen, P., Amann, F.W., Bertel, O., Landmann, R., Lütold, B.E., and Bolli, P. 1980. Plasma catecholamines and cardiac, renal and peripheral vascular adrenoceptor-mediated responses in different age groups of normal and hypertensive subjects. Clin. Exp. Hypertens. 2(3-4): 409-426. doi: 10.3109/10641968009037122.

de Champlain, J., Farley, L., Cousineau, D., and van Ameringen, M.R. 1976. Circulating catecholamine levels in human and experimental hypertension. Circ. Res. 38(2): 109-114. doi: 10.1161/01.RES.38.2.109.

Chiba, T., Itoh, T., Tabuchi, M., Nakazawa, T., and Satou, T. 2012. Interleukin-1 $\beta$ accelerates the onset of stroke in stroke-prone spontaneously hypertensive rats. Mediators Inflamm. 2012: 701976. doi: 10.1155/2012/701976.

Chou, T.C., Yen, M.H., Li, C.Y., and Ding, Y.A. 1998. Alterations of nitric oxide synthase expression with aging and hypertension in rats. Hypertension 31(2): 643-8.

Chrysohoou, C., Pitsavos, C., Panagiotakos, D.B., Skoumas, J., and Stefanadis, C. 2004. Association between prehypertension status and inflammatory markers related to atherosclerotic disease: The ATTICA Study. Am. J. Hypertens. 17(7): 568-73. doi: 10.1016/j.amjhyper.2004.03.675.

Coffman, T.M. 2011. Under pressure: the search for the essential mechanisms of hypertension. Nat. Med. 17(11): 1402-9. doi: 10.1038/nm.2541.

Dalekos, G.N., Elisaf, M., Bairaktari, E., Tsolas, O., and Siamopoulos, K.C. 1997. Increased serum levels of interleukin-1beta in the systemic circulation of patients with essential hypertension: additional risk factor for atherogenesis in hypertensive patients? J. Lab. Clin. Med. 129(3): 300-8.

Dalekos, G.N., Elisaf, M.S., Papagalanis, N., Tzallas, C., and Siamopoulos, K.C. 1996. Elevated interleukin-1 beta in the circulation of patients with essential hypertension before any drug 
therapy: a pilot study. Eur. J. Clin. Invest. 26(10): 936-9.

Derhaschnig, U., Shehata, M., Herkner, H., Bur, A., Woisetschläger, C., Laggner, A.N., and Hirschl, M.M. 2002. Increased levels of transforming growth factor-betal in essential hypertension. Am. J. Hypertens. 15(3): 207-11.

Djordjevic, J., Vuckovic, T., Jasnic, N., and Cvijic, G. 2007. Effect of various stressors on the blood ACTH and corticosterone concentration in normotensive Wistar and spontaneously hypertensive Wistar-Kyoto rats. Gen. Comp. Endocrinol. 153(1-3): 217-20. doi: 10.1016/j.ygcen.2007.02.004.

Ebert, S.N., Balt, S., and Hunter, J. 1994. Egr-1 Activation of Rat Adrenal Phenylethanolamine N-Methyltransferase Gene. J. Biol. Chem.: 20885-20898.

Ebert, S.N., Ficklin, M.B., Her, S., Siddall, B.J., Bell, R.A., Ganguly, K., Morita, K., and Wong, D.L. 1998. Glucocorticoid-dependent action of neural crest factor AP-2: stimulation of phenylethanolamine N-methyltransferase gene expression. J. Neurochem. 70(6): 2286-95. Available from http://www.ncbi.nlm.nih.gov/pubmed/9603193.

Ebert, S.N., and Thompson, R.P. 2001. Embryonic epinephrine synthesis in the rat heart before innervation: association with pacemaking and conduction tissue development. Circ. Res. 88(1): 117-124. doi: 10.1161/01.RES.88.1.117.

Ebert, S.N., and Wong, D.L. 1995. Differential activation of the rat phenylethanolamine Nmethyltransferase gene by Sp1 and Egr-1. J. Biol. Chem. 270(29): 17299-305. doi: 10.1074/jbc.270.29.17299.

Edwards, K.M., Ziegler, M.G., and Mills, P.J. 2007. The potential anti-inflammatory benefits of improving physical fitness in hypertension. J. Hypertens. 25(8): 1533-1542. doi: 10.1097/HJH.0b013e328165ca67.

Esler, M., Eisenhofer, G., Chin, J., Jennings, G., Meredith, I., Cox, H., Lambert, G., Thompson, J., and Dart, A. 1991. Is adrenaline released by sympathetic nerves in man? Clin. Auton. Res. 1(2): 103-108. doi: 10.1007/BF01826204.

Evinger, M.J., Towle, A.C., Park, D.H., Lee, P., and Joh, T.H. 1992. Glucocorticoids stimulate transcription of the rat phenylethanolamine N-methyltransferase (PNMT) gene in vivo and in vitro. Cell. Mol. Neurobiol. 12(3): 193-215. doi: 10.1007/BF00712926.

Feng, M., Whitesall, S., Zhang, Y., Beibel, M., D’Alecy, L., and DiPetrillo, K. 2008. Validation of volume-pressure recording tail-cuff blood pressure measurements. Am. J. Hypertens. 21(12): 1288-91. doi: 10.1038/ajh.2008.301.

Freyschuss, U., Hjemdahl, P., Juhlin-Dannfelt, A., and Linde, B. 1988. Cardiovascular and sympathoadrenal responses to mental stress: influence of beta-blockade. Am. J. Physiol. 
255(6 Pt 2): H1443-51. Available from http://www.ncbi.nlm.nih.gov/pubmed/3202206.

Frohlich, E.D. 1986. Is the spontaneously hypertensive rat a model for human hypertension? J. Hypertens. Suppl. 4(3): S15-S19.

Funder, J.W. 1997. Glucocorticoid and mineralocorticoid receptors: biology and clinical relevance. Annu. Rev. Med. 48(1): 231-240. doi: 10.1146/annurev.med.48.1.231.

Gavrilovic, L., Spasojevic, N., and Dronjak, S. 2010. Subsequent stress increases gene expression of catecholamine synthetic enzymes in cardiac ventricles of chronic-stressed rats. Endocrine 37(3): 425-429. doi: 10.1007/s12020-010-9325-5.

Gavrilovic, L., Spasojevic, N., Zivkovic, M., and Dronjak, S. 2009. Effect of immobilization stress on gene expression of catecholamine biosynthetic enzymes in heart auricles of socially isolated rats. Brazilian J. Med. Biol. Res. 42(12): 1185-1190. doi: 10.1590/S0100879X2009005000036.

Goldstein, D.S. 1983. Plasma catecholamines and essential hypertension. An analytical review. Hypertension 5(1): 86-99.

Grassi, G., Quarti-Trevano, F., Seravalle, G., and Dell'Oro, R. 2006. Sympathetic overdrive and cardiovascular risk in the metabolic syndrome. Hypertens. Res. Off. J. Japanese Soc. Hypertens. 17(6): 473-481. doi: 10.1291/hypres.29.839.

Haan, C., and Behrmann, I. 2007. A cost effective non-commercial ECL-solution for Western blot detections yielding strong signals and low background. J. Immunol. Methods 318(1-2): 11-9. doi: 10.1016/j.jim.2006.07.027.

Her, S., Claycomb, R., Tai, T.C., and Wong, D.L. 2003. Regulation of the rat phenylethanolamine N-methyltransferase gene by transcription factors Sp1 and MAZ. Mol. Pharmacol. 64(5): 1180-8. doi: 10.1124/mol.64.5.1180.

Huang, M.H., Bahl, J.J., Wu, Y., Hu, F., Larson, D.F., Roeske, W.R., and Ewy, G.A. 2005. Neuroendocrine properties of intrinsic cardiac adrenergic cells in fetal rat heart. Am. J. Physiol. Heart Circ. Physiol. 288(2): H497-H503. doi: 10.1152/ajpheart.00591.2004.

Imagawa, M., Chiu, R., and Karin, M. 1987. Transcription factor AP-2 mediates induction by two different signal-transduction pathways: protein kinase C and cAMP. Cell 51(2): 251260. doi: 10.1016/0092-8674(87)90152-8.

Jablonskis, L.T., and Howe, P.R. 1994. Elevated plasma adrenaline in spontaneously hypertensive rats. Blood Press. 3(1-2): 106-11. Available from http://www.ncbi.nlm.nih.gov/pubmed/8199710.

Kennedy, B., Elayan, H., and Ziegler, M.G. 1993. Glucocorticoid hypertension and nonadrenal phenylethanolamine N-methyltransferase. Hypertension 21(4): 415-9. doi: 


\subsection{1/01.HYP.21.4.415.}

Kennedy, B., and Ziegler, M.G. 1991. Cardiac epinephrine synthesis. Regulation by a glucocorticoid. Circulation 84(2): 891-895. doi: 10.1161/01.CIR.84.2.891.

Kennedy, B., and Ziegler, M.G. 2000. Ontogeny of epinephrine metabolic pathways in the rat: Role of glucocorticoids. Int. J. Dev. Neurosci. 18(1): 53-59. doi: 10.1016/S07365748(99)00106-9.

Koike, G., Jacob, H., and Krieger, J. 1995. Investigation of the Phenylethanolamine NMethyltransferase Gene as a Candidate Gene for Hypertension. Hypertension: 595-601. Available from http://hyper.ahajournals.org/content/26/4/595.short [accessed 25 March 2014].

Krizanová, O., Micutková, L., Jeloková, J., Filipenko, M., Sabban, E., and Kvetnanský, R. 2001. Existence of cardiac PNMT mRNA in adult rats: elevation by stress in a glucocorticoiddependent manner. Am. J. Physiol. Heart Circ. Physiol. 281(3): H1372-9. Available from http://www.ncbi.nlm.nih.gov/pubmed/11514309.

Krizanova, O., Myslivecek, J., Tillinger, a, Jurkovicova, D., and Kubovcakova, L. 2007. Adrenergic and calcium modulation of the heart in stress: from molecular biology to function. Stress 10(2): 173-184. doi: 10.1080/10253890701305754.

Kvetnansky, R., Micutkova, L., Kubovcakova, L., Sabban, E.L., Palkovits, M., and Krizanova, O. 2004. Localization and regulation of phenylethanolamine N-methyltransferase gene expression in the heart of rats and mice during stress. Ann. N. Y. Acad. Sci. 1018(4212): 405-417. doi: 10.1196/annals.1296.050.

Kvetňanský, R., Pacák, K., Fukuhara, K., Viskupič, E., Hiremagalur, B., Nankova, B., Goldstein, D.S., Sabban, E.L., and Kopin, I.J. 1995. Sympathoadrenal System in Stress. Ann. N. Y. Acad. Sci. 771(1 Stress): 131-158. doi: 10.1111/j.1749-6632.1995.tb44676.x.

Majewski, H., Tung, L.H., and Rand, M.J. 1981. Adrenaline-induced hypertension in rats. J. Cardiovasc. Pharmacol. 3(1): 179-85. Available from http://www.ncbi.nlm.nih.gov/pubmed/6160347.

McEwen, B.S., De Kloet, E.R., and Rostene, W. 1986. Adrenal steroid receptors and actions in the nervous system. Physiol. Rev. 66(4): 1121-1188.

Miguel-Carrasco, J.L., Zambrano, S., Blanca, A.J., Mate, A., and Vázquez, C.M. 2010. Captopril reduces cardiac inflammatory markers in spontaneously hypertensive rats by inactivation of NF-kB. J. Inflamm. (Lond). 7: 21. doi: 10.1186/1476-9255-7-21.

Moorman, A.F.M., de Jong, F., Denyn, M.M.F.J., and Lamers, W.H. 1998. Development of the Cardiac Conduction System. Circ. Res. 82(6): 629-644. doi: 10.1161/01.RES.82.6.629. 
Morita, K., Bell, R., Siddall, B., and Wong, D. 1996. Neural stimulation of Egr-1 messenger RNA expression in rat adrenal gland: possible relation to phenylethanolamine Nmethyltransferase gene regulation. J. Pharmacol. Exp. Ther. 279(1): 379-385. Available from http://jpet.aspetjournals.org/content/279/1/379.abstract [accessed 7 May 2014].

Morita, K., and Wong, D.L. 1996. Role of Egr-1 in cholinergic stimulation of phenylethanolamine N-methyltransferase promoter. J. Neurochem. 67(4): 1344-1351.

Müller, F.U., Loser, K., Kleideiter, U., Neumann, J., von Wallbrunn, C., Dobner, T., Scheld, H.H., Bantel, H., Engels, I.H., Schulze-Osthoff, K., and Schmitz, W. 2004. Transcription factor AP-2alpha triggers apoptosis in cardiac myocytes. Cell Death Differ. 11(5): 485-493. doi: $10.1038 /$ sj.cdd.4401383.

Müller, F.U., Neumann, J., and Schmitz, W. 2000. Transcriptional regulation by cAMP in the heart. Mol. Cell. Biochem. 212(1-2): 11-17. doi: 10.1023/A:1007176030884.

Nguyen, P., Peltsch, H., de Wit, J., Crispo, J., Ubriaco, G., Eibl, J., and Tai, T.C. 2009.

Regulation of the phenylethanolamine N-methyltransferase gene in the adrenal gland of the spontaneous hypertensive rat. Neurosci. Lett. 461(3): 280-4. Elsevier Ireland Ltd. doi: 10.1016/j.neulet.2009.06.022.

Parissis, J.T., Korovesis, S., Giazitzoglou, E., Kalivas, P., and Katritsis, D. 2002. Plasma profiles of peripheral monocyte-related inflammatory markers in patients with arterial hypertension. Correlations with plasma endothelin-1. Int. J. Cardiol. 83(1): 13-21.

Peeters, A.C., Netea, M.G., Janssen, M.C., Kullberg, B.J., Van der Meer, J.W., and Thien, T. 2001. Pro-inflammatory cytokines in patients with essential hypertension. Eur. J. Clin. Invest. 31(1): 31-6.

Rabkin, S.W. 2009. The role of interleukin 18 in the pathogenesis of hypertension-induced vascular disease. Nat. Clin. Pract. Cardiovasc. Med. 6(3): 192-199. doi: 10.1038/ncpcardio1453.

Reisine, T.D. 1984. Cellular mechanisms regulating adrenocorticotropin release. J. Recept. Res. 4(1-6): 291-300. doi: 10.3109/10799898409042556.

Rodríguez-Flores, J.L., Zhang, K., Kang, S.W., Wen, G., Ghosh, S., Friese, R.S., Mahata, S.K., Subramaniam, S., Hamilton, B. a., and O’Connor, D.T. 2010. Conserved regulatory motifs at phenylethanolamine N-methyltransferase (PNMT) are disrupted by common functional genetic variation: An integrated computational/experimental approach. Mamm. Genome 21(3-4): 195-204. doi: 10.1007/s00335-010-9253-y.

Rosmaninho-Salgado, J., Álvaro, A.R., Grouzmann, E., Duarte, E.P., and Cavadas, C. 2007. Neuropeptide Y regulates catecholamine release evoked by interleukin-1 $\beta$ in mouse chromaffin cells. Peptides 28(2): 310-314. doi: 10.1016/j.peptides.2006.11.015. 
Ross, M.E., Evinger, M.J., Hyman, S.E., Carroll, J.M., Mucke, L., Comb, M., Reis, D.J., Joh, T.H., and Goodman, H.M. 1990. Identification of a functional glucocorticoid response element in the phenylethanolamine $\mathrm{N}$-methyltransferase promoter using fusion genes introduced into chromaffin cells in primary culture. J. Neurosci. 10(2): 520-530.

Rumantir, M.S., Jennings, G.L., Lambert, G.W., Kaye, D.M., Seals, D.R., and Esler, M.D. 2000. The "adrenaline hypothesis" of hypertension revisited: evidence for adrenaline release from the heart of patients with essential hypertension. J. Hypertens. 18: 717-723. doi: 10.1097/00004872-200018060-00009.

Rupp, H., Felbier, H.R., Bukhari, a R., and Jacob, R. 1984. Modulation of myosin isoenzyme populations and activities of monoamine oxidase and phenylethanolamine-Nmethyltransferase in pressure loaded and normal rat heart by swimming exercise and stress arising from electrostimulation in pairs. Can. J. Physiol. Pharmacol. 62(9): 1209-1218. doi: 10.1139/y84-202.

Saavedra, J.M., Grobecker, H., and Axelrod, J. 1976. Adrenaline-forming enzyme in brainstem: elevation in genetic and experimental hypertension. Science 191(4226): 483-484. doi: $10.1126 /$ science. 1246633 .

Sanz-Rosa, D., Cediel, E., de las Heras, N., Miana, M., Balfagón, G., Lahera, V., and Cachofeiro, V. 2005a. Participation of aldosterone in the vascular inflammatory response of spontaneously hypertensive rats: role of the NFkappaB/IkappaB system. J. Hypertens. 23(6): 1167-1172.

Sanz-Rosa, D., Oubiña, M.P., Cediel, E., de Las Heras, N., Vegazo, O., Jiménez, J., Lahera, V., and Cachofeiro, V. 2005b. Effect of AT1 receptor antagonism on vascular and circulating inflammatory mediators in SHR: role of NF-kappaB/IkappaB system. Am. J. Physiol. Heart Circ. Physiol. 288(1): H111-5. doi: 10.1152/ajpheart.01061.2003.

Scheinman, R.I., Cogswell, P.C., Lofquist, A.K., and Baldwin, A.S. 1995. Role of Transcriptional Activation of IkappaBalpha in Mediation of Immunosuppression by Glucocorticoids. Science (80-. ). 270(5234): 283-286. doi: 10.1126/science.270.5234.283.

Van Stee, E.W. 1978. Autonomic innervation of the heart. Environ. Health Perspect. 26: 151158. Available from http://www.ncbi.nlm.nih.gov/pmc/articles/PMC1637264/.

Tai, T.C., Claycomb, R., Her, S., Bloom, A.K., and Wong, D.L. 2002. Glucocorticoid responsiveness of the rat phenylethanolamine N-methyltransferase gene. Mol. Pharmacol. 61(6): 1385-92. Available from http://www.ncbi.nlm.nih.gov/pubmed/12021400.

Tai, T.C., Claycomb, R., Siddall, B.J., Bell, R.A., Kvetnansky, R., and Wong, D.L. 2007. Stressinduced changes in epinephrine expression in the adrenal medulla in vivo. J. Neurochem. 101(4): 1108-18. doi: 10.1111/j.1471-4159.2007.04484.x. 
Tai, T.C., Morita, K., and Wong, D.L. 2001. Role of Egr-1 in cAMP-dependent protein kinase regulation of the phenylethanolamine N-methyltransferase gene. J. Neurochem. 76(6): 1851-1859. doi: 10.1046/j.1471-4159.2001.00189.x.

Tai, T.C., and Wong, D.L. 2003. Protein kinase A and protein kinase C signaling pathway interaction in phenylethanolamine $\mathrm{N}$-methyltransferase gene regulation. J. Neurochem. 85(3): 816-829. doi: 10.1046/j.1471-4159.2003.01728.x.

Thomas, S.A., Matsumoto, A.M., and Palmiter, R.D. 1995. Noradrenaline is essential for mouse fetal development. Nature 374(6523): 643-646. doi: 10.1038/374643a0.

Tillinger, A., Bruderova, V., Kubovcakova, L., Zeman, M., Kopacek, J., Novakova, M., Kvetnansky, R., and Krizanova, O. 2006. Gene expression of the phenylethanolamine Nmethyltransferase is differently modulated in cardiac atria and ventricles. Gen. Physiol. Biophys. 25(4): 355-364.

Uchoa, E.T., Aguilera, G., Herman, J.P., Fiedler, J.L., Deak, T., and de Sousa, M.B.C. 2014. Novel aspects of glucocorticoid actions. J. Neuroendocrinol. (2): 557-572. doi: 10.1111/jne.12157.

Unsworth, B.R., Hayman, G.T., Carroll, A., and Lelkes, P.I. 1999. Tissue-specific alternative mRNA splicing of phenylethanolamine N-methyltransferase (PNMT) during development by intron retention. Int. J. Dev. Neurosci. 17(1): 45-55. Available from http://www.ncbi.nlm.nih.gov/pubmed/10219960.

Wong, D.L. 2006. Epinephrine biosynthesis: hormonal and neural control during stress. Cell. Mol. Neurobiol. 26(4-6): 891-900. doi: 10.1007/s10571-006-9056-6.

Wong, D.L., Anderson, L.J., and Tai, T.C. 2002. Cholinergic and peptidergic regulation of phenylethanolamine N-methyltransferase gene expression. Ann. N. Y. Acad. Sci. 971: 1926.

Wong, D.L., Bildstein, C.L., Siddall, B., Lesage, A., and Yoo, Y.S. 1993. Neural regulation of phenylethanolamine N-methyltransferase in vivo: transcriptional and translational changes. Brain Res. Mol. Brain Res. 18(1-2): 107-114.

Wong, D.L., Hayashi, R.J., and Ciaranello, R.D. 1985. Regulation of biogenic amine methyltransferases by glucocorticoids via $\mathrm{S}$-adenosylmethionine and its metabolizing enzymes, methionine adenosyltransferase and S-adenosylhomocysteine hydrolase. Brain Res. 330(2): 209-216. doi: 10.1016/0006-8993(85)90679-1.

Wong, D.L., Lesage, A., Siddall, B., and Funder, J.W. 1992. Glucocorticoid regulation of phenylethanolamine N-methyltransferase in vivo. FASEB J. 6(14): 3310-3315.

Wong, D.L., Siddall, B.J., Ebert, S.N., Bell, R.A., and Her, S. 1998. Phenylethanolamine N- 
methyltransferase gene expression: synergistic activation by Egr-1, AP-2 and the glucocorticoid receptor. Brain Res. Mol. Brain Res. 61(1-2): 154-61. Available from http://www.ncbi.nlm.nih.gov/pubmed/9795195.

Yamamoto, K.R. 1985. Steroid Receptor Regulated.

Zhou, Q.Y., Quaife, C.J., and Palmiter, R.D. 1995. Targeted disruption of the tyrosine hydroxylase gene reveals that catecholamines are required for mouse fetal development. Nature 374(6523): 640-643. doi: 10.1038/374640a0.

Ziegler, M.G., Bao, X., Kennedy, B.P., Joyner, A., and Enns, R. 2002. Location, development, control, and function of extraadrenal phenylethanolamine N-methyltransferase. Ann. N. Y. Acad. Sci. 971: 76-82. 


\section{Figure Legends}

Figure 1. Blood pressure and heart rate measurements for WKY and SHR animals at 16weeks of age. Physiological measurements were taken using the non-invasive tail-cuff plethysmography method (CODA 6; Kent Scientific). Blood pressure is shown in mmHg. Heart rate is shown in beats per minute $(\mathrm{bpm})$. Data is expressed as the mean \pm SEM $\quad(n=6)$. Statistical significance between WKY and SHR is shown by $* p<0.05 ; * * p<0.01 ; * * * p<$ 0.001 .

Figure 2. Plasma levels of corticosterone and cytokines in WKY and SHR. (A) Corticosterone plasma concentrations, (B) and (C) cytokine concentrations were quantified using Milliplex immunodetection assays. Data is expressed as the mean \pm SEM $(n=4-6)$. Statistical significance between WKY and SHR is shown by $* p<0.05 ; * * p<0.01 ; * * * p<0.001$.

Figure 3. PNMT mRNA expression in SHR and WKY for all chambers of the heart. Transcription factor mRNA was determined as described in methods for PNMT (A) Representative gel images following RT-PCR with intron-retaining PNMT (top band, 422bp) and intronless PNMT (bottom band 312bp). (B) Intron-retaining (inactive) PNMT. (C) Intronless (active) PNMT. LV (Left Ventricle), RV (Right Ventricle), LA (Left Atrium), RA (Right Atrium). Results are normalized relative to the housekeeper 28S RNA and then normalized to the left atrium (LA) of WKY. Data expressed in arbitrary units as the mean \pm SEM $(n=4)$. Statistical significance between WKY left atrium and SHR is shown by * $p<0.05 ; * * p<0.01$; *** $p<0.001$. Statistical significance between WKY and SHR is shown by $\dagger p<0.05 ; \dagger \dagger p<$ 0.01 ; †† $p<0.001$. Statistical significance between SHR or WKY chambers is shown by \# $p<$ 0.05; \#\# $p<0.01$; \#\#\# $p<0.001$. 
Figure 4. Transcription factor mRNA expression in the hearts of SHR and WKY. Transcription factor mRNA was determined as described in methods for (A) Sp1, (B) GR, (C) AP-2, and (D) Egr-1 with representative gel images following RT-PCR. Results are normalized relative to the housekeeper 28S RNA and then normalized to the left atrium (LA) of WKY. Data is expressed in arbitrary units as the mean \pm SEM $(n=4)$. Statistical significance between WKY left atrium and SHR is shown by * $p<0.05 ; * * p<0.01 ; * * * p<0.001$. Statistical significance between WKY and SHR is shown by $\dagger p<0.05$; $\dagger \dagger p<0.01$; $\dagger \dagger \uparrow p<0.001$. Statistical significance between SHR chambers is shown by \# $p<0.05$; \#\# $p<0.01$; \#\#\# $p<0.001$.

Figure 5. Transcription factor protein expression in SHR compared to WKY for all chambers of the heart. Whole cell protein extracts were prepared from heart tissue homogenates as described in methods and western analysis performed for (A) Sp1, (B) GR, (C) AP-2, and (D) Egr-1 with representative autoradiogram after western blot. Results are normalized to respective WKY heart chamber and expressed in arbitrary units. Data is expressed as the mean $\pm \operatorname{SEM}(n=4)$. Statistical significance between WKY and SHR is shown by $* p<$ $0.05 ; * * p<0.01 ; * * * p<0.001$.

Figure 6. Transcription factor-promoter functionality in the hearts of SHR and WKY. Gel mobility shift assays were performed using protein extracts and radiolabeled, double-stranded oligonucleotides encoding the transcription factors consensus binding sequences for (A) Sp1, (B) GR, (C) AP-2, and (D) Egr-1 with representative autoradiogram after electrophoretic mobility shift assay. Results are normalized to respective WKY heart chamber and expressed in arbitrary units. Data is expressed as the mean $\pm \operatorname{SEM}(n=4)$. Statistical significance between WKY and SHR is shown by $* p<0.05 ; * * p<0.01 ; * * * p<0.001$. 


\section{FIGURES}

Figure 1.

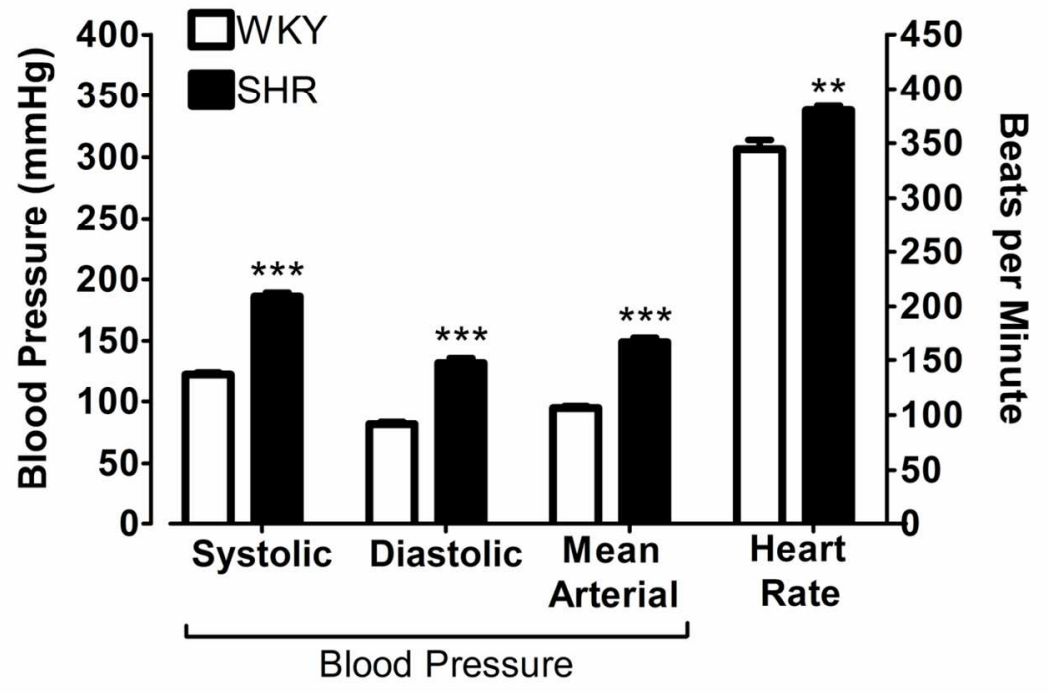

Figure 2.

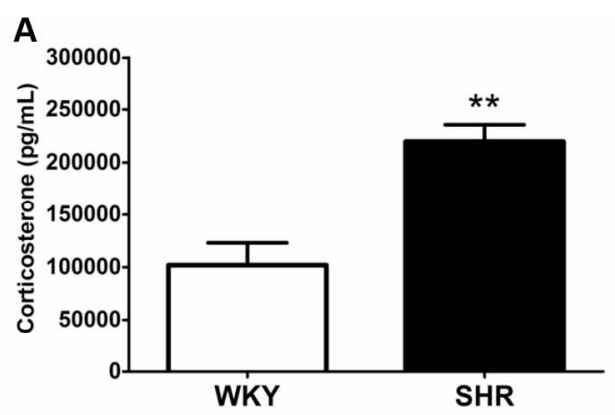

$165 \times 199 m m(300 \times 300$ DPI $)$ 
Fig. 2B

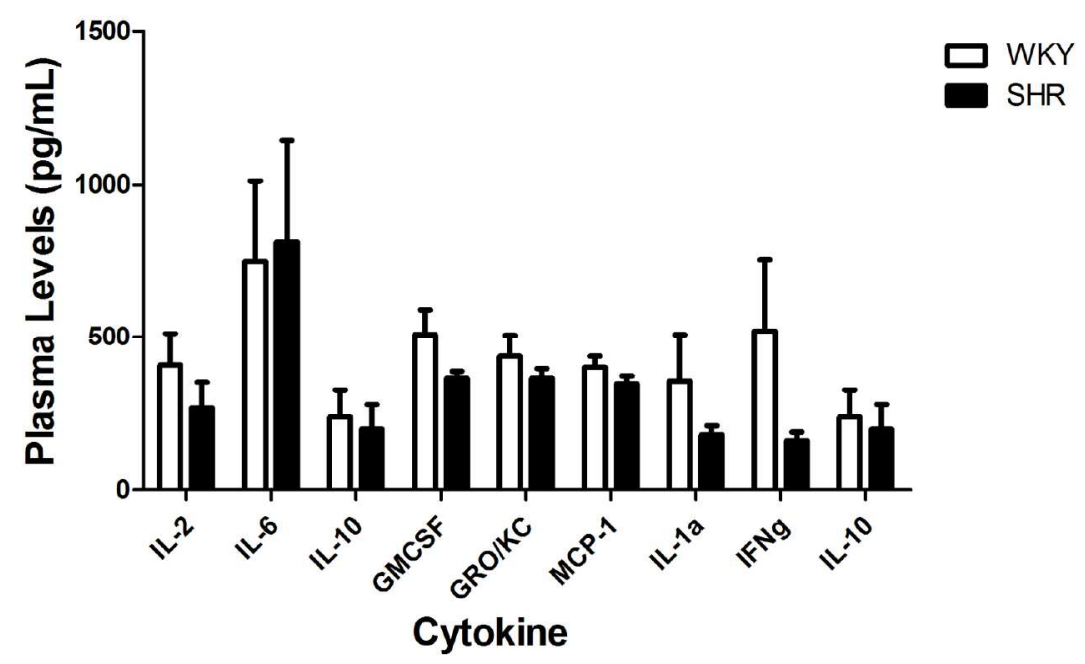

Fig. 2C

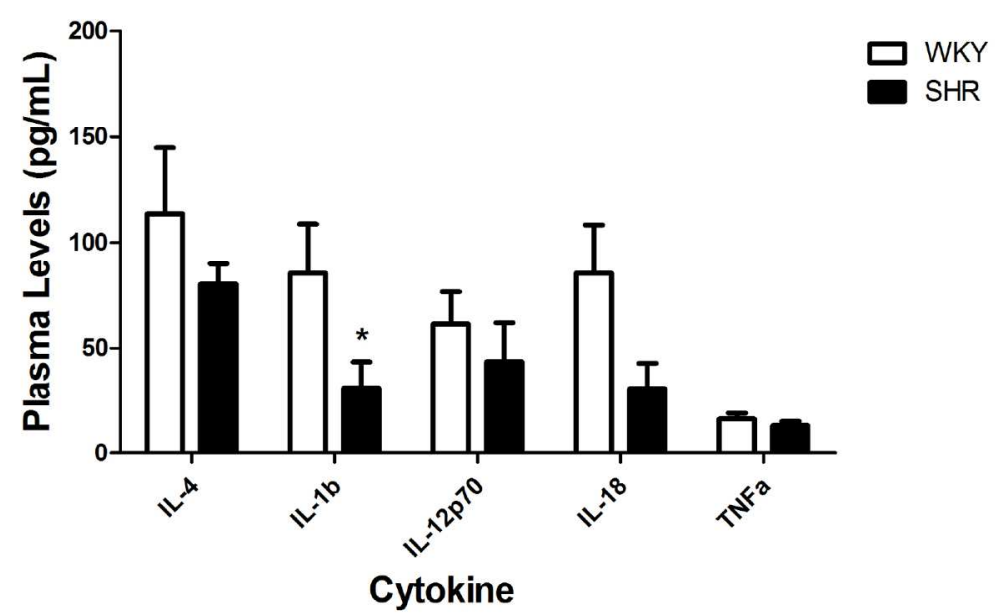

$165 \times 186 \mathrm{~mm}(300 \times 300$ DPI $)$ 
Figure 3.
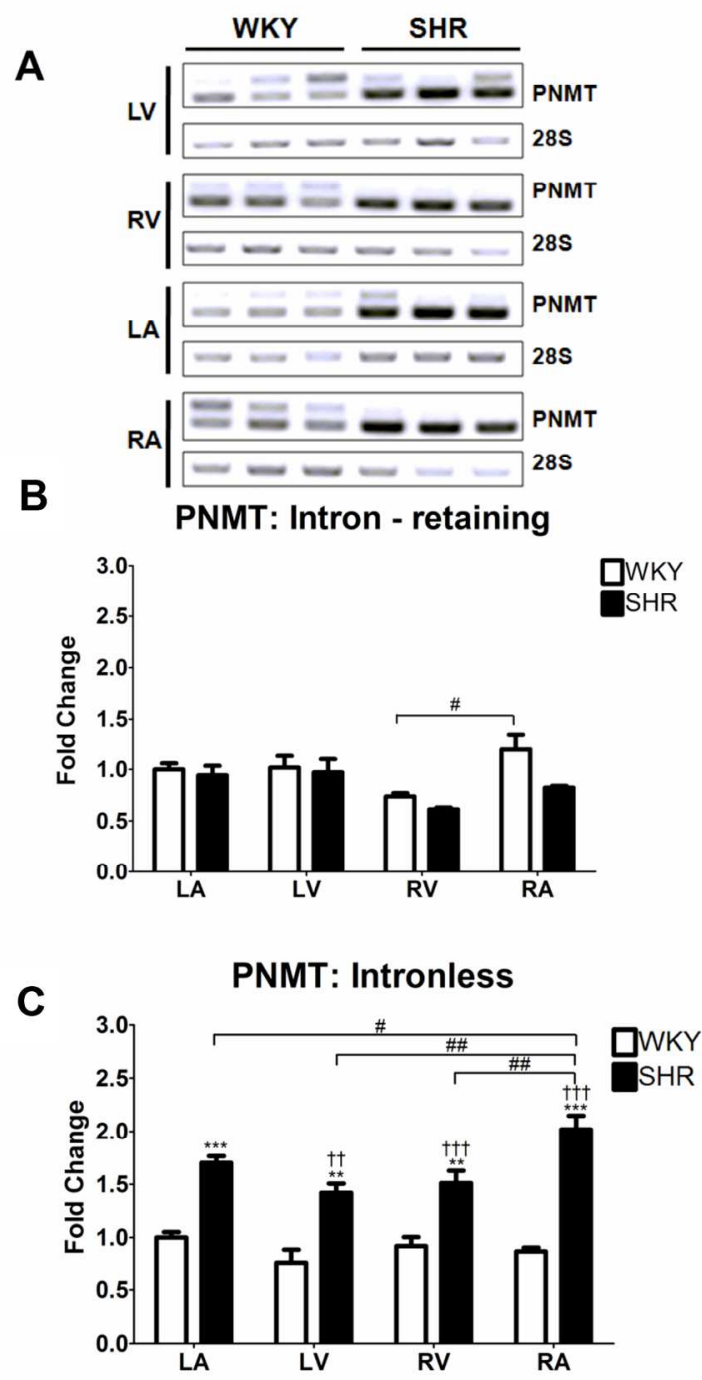

$175 \times 201 \mathrm{~mm}(300 \times 300$ DPI $)$ 
Figure 4.
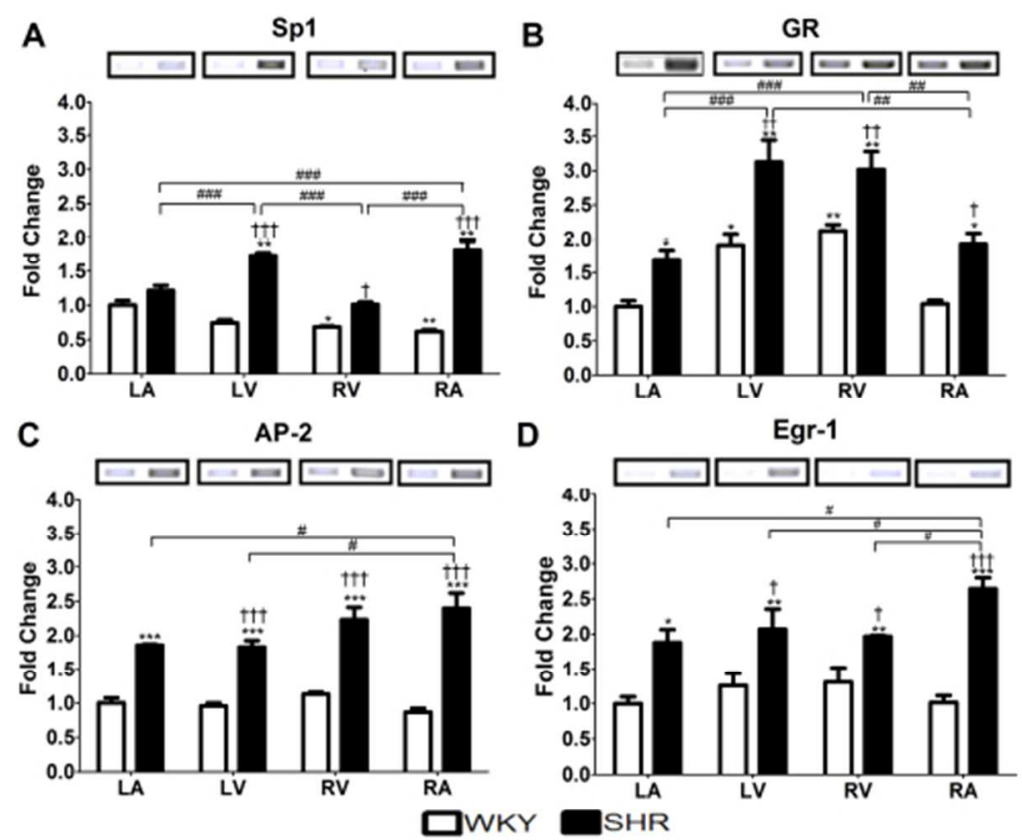

$53 \times 45 \mathrm{~mm}(300 \times 300$ DPI $)$ 
Figure 5.

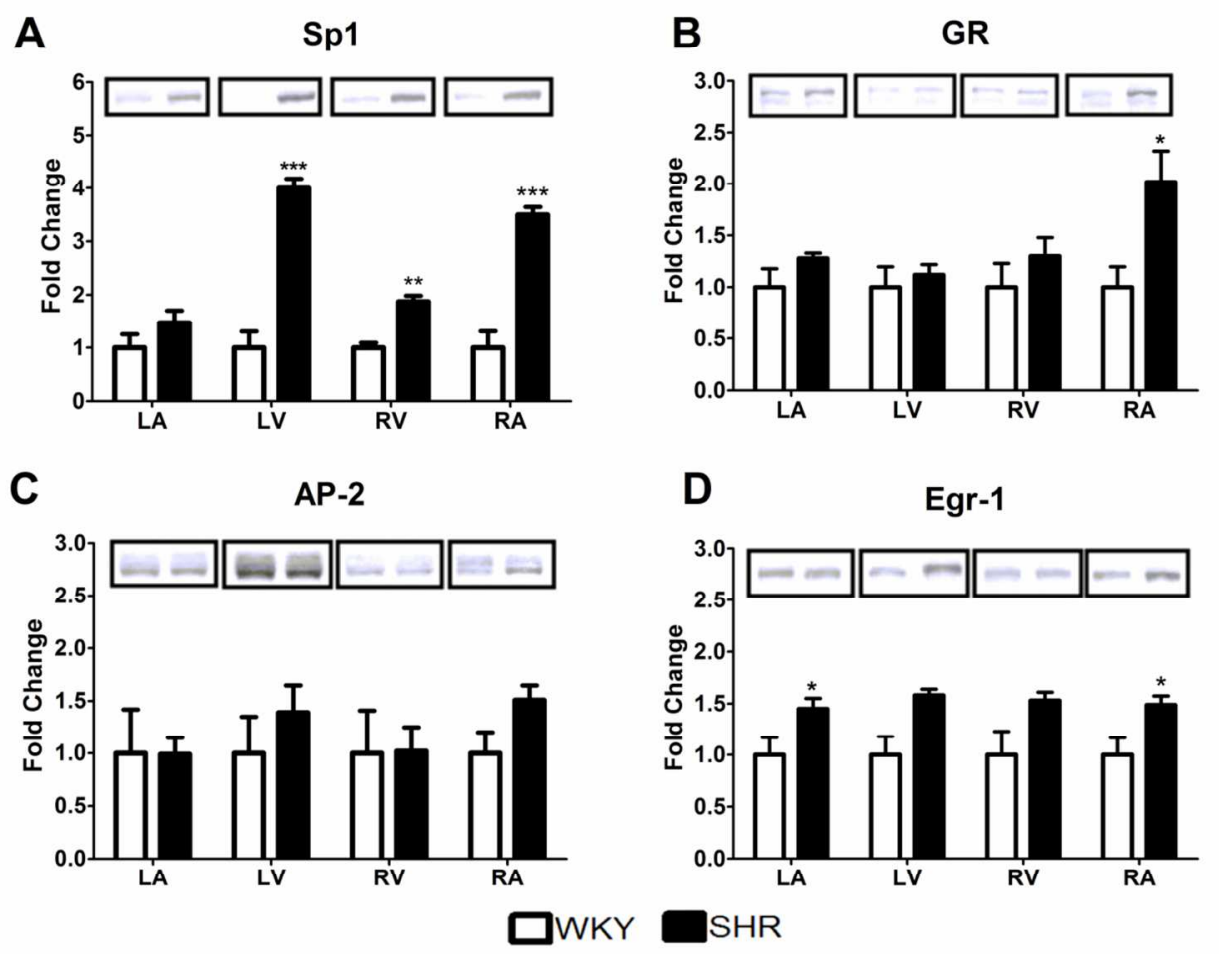

$169 \times 143 \mathrm{~mm}(300 \times 300 \mathrm{DPI})$ 
Figure 6.

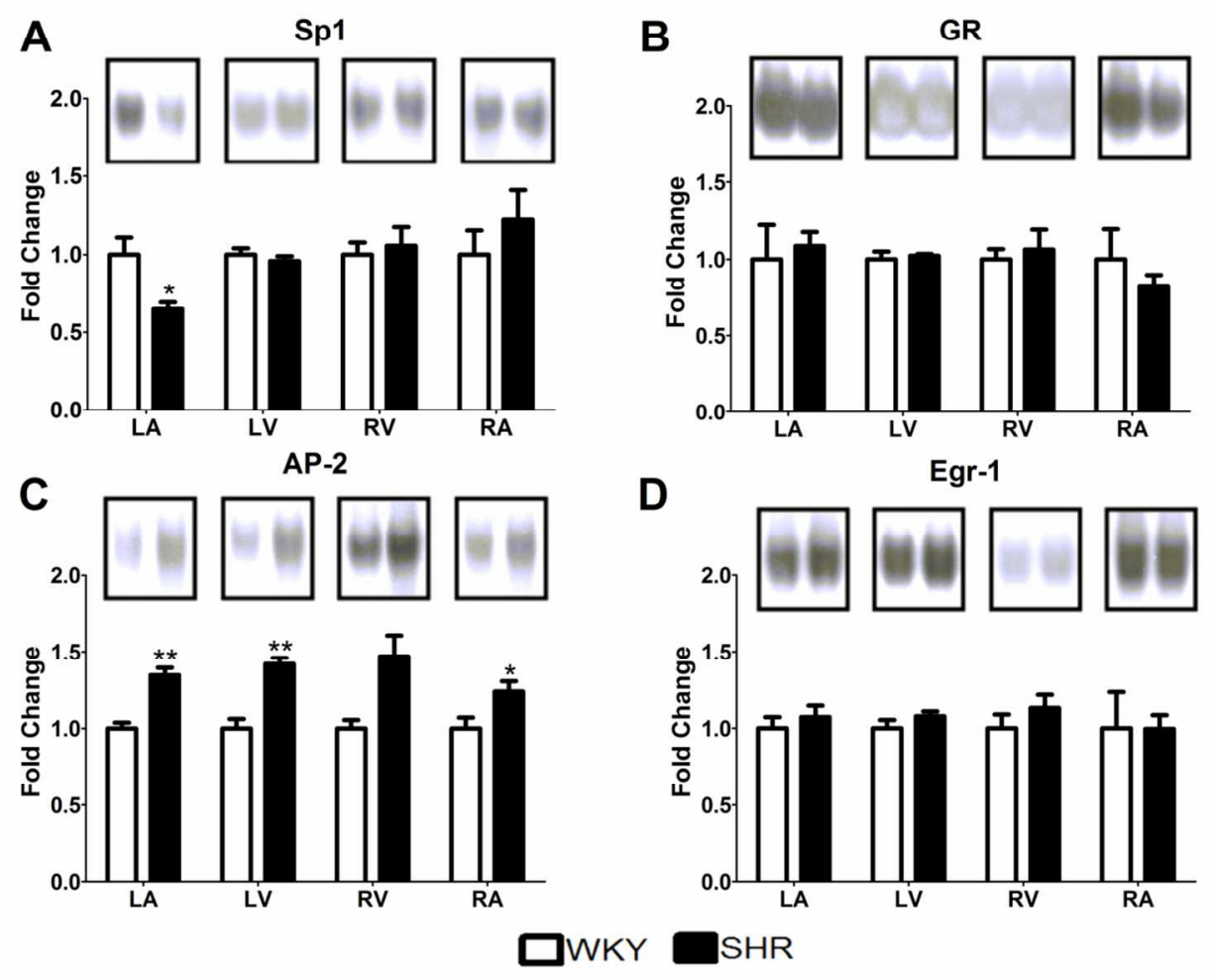

$170 \times 147 \mathrm{~mm}(300 \times 300 \mathrm{DPI})$ 